Review Article

\title{
A Review: Mechanism of Phyllanthus urinaria in Cancers-NF- $\kappa$ B, P13K/AKT, and MAPKs Signaling Activation
}

\author{
Roland Osei. Saahene $\mathbb{D}^{1},{ }^{1}$ Elvis Agbo, ${ }^{2}$ Precious Barnes, ${ }^{3}$ Ewura Seidu Yahaya, ${ }^{4}$ \\ Benjamin Amoani, ${ }^{5}$ Samuel Victor Nuvor, ${ }^{1}$ and Perditer Okyere ${ }^{6}$ \\ ${ }^{1}$ Department of Microbiology and Immunology, School of Medical Sciences, College of Health and Allied Sciences, \\ University of Cape Coast, Cape Coast, Ghana \\ ${ }^{2}$ Department of Human Anatomy, Histology and Embryology, College of Medicine, Jinggangshan University, Jian City, \\ Jiangxi Province, China \\ ${ }^{3}$ Department of Physician Assistant Studies, School of Allied Health Sciences, College of Health and Allied Sciences, \\ University of Cape Coast, Cape Coast, Ghana \\ ${ }^{4}$ Department of Pharmacology, School of Medical Sciences, College of Health and Allied Sciences, University of Cape Coast, \\ Cape Coast, Ghana \\ ${ }^{5}$ Department of Biomedical Sciences, School of Allied Health Sciences, College of Health and Allied Sciences, \\ University of Cape Coast, Cape Coast, Ghana \\ ${ }^{6}$ Department of Medicine, School of Medicine and Dentistry, Kwame Nkrumah University of Science and Technology, \\ Kumasi, Ghana \\ Correspondence should be addressed to Roland Osei. Saahene; rsaahene@uccsms.edu.gh
}

Received 16 April 2021; Revised 1 July 2021; Accepted 19 August 2021; Published 26 August 2021

Academic Editor: Fahmida Alam

Copyright (C) 2021 Roland Osei. Saahene et al. This is an open access article distributed under the Creative Commons Attribution License, which permits unrestricted use, distribution, and reproduction in any medium, provided the original work is properly cited.

Phyllanthus urinaria has been characterized for its several biological and medicinal effects such as antiviral, antibacterial, antiinflammatory, anticancer, and immunoregulation. In recent years, Phyllanthus urinaria has demonstrated potential to modulate the activation of critical pathways such as NF- $\kappa \mathrm{B}, \mathrm{P} 13 \mathrm{~K} / \mathrm{AKT}$, and ERK/JNK/P38/MAPKs associated with cell growth, proliferation, metastasis, and apoptotic cell death. To date, there is much evidence indicating that modulation of cellular signaling pathways is a promising approach to consider in drug development and discovery. Thus, therapies that can regulate cancer-related pathways are longed-for in anticancer drug discovery. This review's focus is to provide comprehensive knowledge on the anticancer mechanisms of Phyllanthus urinaria through the regulation of NF- $\kappa \mathrm{B}, \mathrm{P} 13 \mathrm{~K} / \mathrm{AKT}$, and ERK/JNK/P38/MAPKs signaling pathways. Thus, the review summarizes both in vitro and in vivo effects of Phyllanthus urinaria extracts or bioactive constituents with emphasis on tumor cell apoptosis. The literature information was obtained from publications on Google Scholar, PubMed, Web of Science, and EBSCOhost. The key words used in the search were "Phyllanthus" or "Phyllanthus urinaria" and cancer. P. urinaria inhibits cancer cell proliferation via inhibition of NF- $\kappa \mathrm{B}, \mathrm{P} 13 \mathrm{~K} / \mathrm{AKT}$, and MAPKs (ERK, JNK, P38) pathways to induce apoptosis and prevents angiogenesis. It is expected that understanding these fundamental mechanisms may help stimulate additional research to exploit Phyllanthus urinaria and other natural products for the development of novel anticancer therapies in the future.

\section{Introduction}

Phyllanthus urinaria (Euphorbiaceae) is a traditional pharmaceutical plant that has been characterized for its several biological and medicinal effects such as antiviral, antibacterial, anti-inflammatory, and immunoregulation [1-4]. In recent years, $P$. urinaria has demonstrated to possess anticancer properties on melanoma, osteosarcoma, lung cancer, breast cancer, and prostate cancer cells [5-9]. The plant has been shown to significantly inhibit the 
proliferation of tumor cells via induction of apoptosis by modulating various cell signaling pathways $[10,11]$. The modulation of signal transduction pathways by chemical compounds is critically important and has attained much attention among researchers. Therefore, the potential of several natural products to regulate cell signaling pathways involved in the proliferation and development of cancers has been demonstrated. To date, there is much evidence that indicates that modulation of cellular signaling transduction pathways is a promising approach to consider in drug development and discovery. This review provides comprehensive knowledge on the anticancer mechanisms of $P$. urinaria through regulation of critical pathways such as nuclear factor-kappa B (NF- $\kappa \mathrm{B})$, protein kinase B (PI3K/ $\mathrm{AKT}$ ), and mitogen-activated protein kinases MAPKs (ERK/ JNK/P38) with emphasis on tumor cell apoptosis.

\section{Methodology}

The literature information was obtained from publications on Google Scholar, PubMed, Web of Science, and EBSCOhost. The key words used in the search were "Phyllanthus" or "Phyllanthus urinaria" and cancer. All potential fulltexts of eligible articles and research papers with title/abstract were included, and no language restrictions applied. Additional articles were obtained by tracking citations from the selected publications or directly accessing the journals' websites.

2.1. Apoptosis and Cancer. Apoptosis is gene-controlled programmed cell death by which multicellular organisms get rid of unwanted cells that threaten their survival, and by so doing intracellular homeostasis is maintained. Tumorigenesis, a multistep complex process that leads to malignant transformation of normal cells due to genetic alterations, is characterized by physiologic imbalance between proliferation and apoptosis. The loss of apoptosis can result in the growth of additional vasculature to provide nourishment to sustain continuous tumor growth. Apoptosis is identified by distinct morphological and biochemical hallmarks. Biochemically, it is characterized by mitochondrial release of specific mediators into the cytoplasm, stimulation of caspase mechanisms, and changes in membrane uniformity. The morphological hallmarks of apoptosis include chromatin degradation and condensation, membrane blebbing, and cell shrinkage.

Apoptosis in mammals is broadly categorized into (i) extrinsic pathway, which is initiated by the tumor necrosis factor superfamily receptors, and (ii) intrinsic pathway, which is activated by damaged DNA, and they correlate with external and internal signaling, respectively. However, the apoptotic process is highly regulated by caspases and distinct protein-protein interaction, which cooperate to activate each other in a proteolytic cascade. Apoptotic signaling activation of the caspases results in the cleavage of cellular components used for normal cell function. The apoptotic cells are then ultimately broken into apoptotic bodies, which are subsequently cleared by phagocytes via phagocytosis to prevent inflammatory response. Cancer prevention is one of the principal roles of apoptosis [12]. Deficiencies in the programmed cell death machinery of cells characterize formation of tumors and are pertinent for malignant alteration, tumor development and advancement, angiogenesis, and metastasis $[13,14]$. Thus, survival and growth of most cancer cells are due to their hallmark of acquired resistance to induction of apoptosis. Dysregulation of cellular machinery involved in recognizing important extracellular and intracellular stimuli as well as signaling pathways responsible for apoptosis enable cancer cells to evade apoptosis and survive to increase their invasiveness [15]. The suppression of caspase function leads to overexpression of Bcl-2 antiapoptotic protein and underexpression of Bax and or Bak proapoptotic proteins, which affect apoptotic pathways and promote cancer cell formation [12].

2.2. Apoptosis and Signaling Pathways. Scientific evidence supporting apoptosis in various pathological and physiological models has provided remarkable knowledge for understanding the key functions of apoptosis in the development of cancers in humans. Activation of mechanisms regulating apoptosis can result in increased accumulation of cells or decreased cell removal.

The goal of cancer therapies is to protect normal cells without causing much damage and promote apoptosis of cancer cells. Existing cancer therapies act by direct toxicity and induction of apoptosis; hence, resistance to apoptosis may in part explain why some cancer therapeutics fail. Novel treatment approaches designed to exploit our knowledge of apoptotic mechanisms via signal transduction pathways may provide a unique therapeutic advantage for the treatment of various cancers in the future. Apoptosis can be activated and inhibited by a variety of stimuli and factors. Phenotypic features of ER-negative breast cancer occur due to unsuitable NF-kappa B signal expression and function, activating abnormal cell proliferation and inhibition of apoptosis [16]. Apoptotic signals that cause an imbalance of either declined cell death or increased cell proliferation and survival can result in cancer. The induction of continuous cell proliferation via NF- $\kappa \mathrm{B}, \mathrm{P} 13 \mathrm{~K} / \mathrm{AKT}$, and MAPKs (/ERK/JNK/P38) signaling inhibits apoptosis subject to the activation of one or more pathways associated with the cell cycle. Therefore, targeting signaling pathways involved in cell proliferation, apoptosis, and differentiation may provide novel therapeutics for the treatment of cancers.

2.3. Phyllanthus urinaria Modulates $N F-\kappa B, P 13 K / A K T$, and $M A P K s$ Activation. Tumor growth, development, and metastasis are hallmarks of aberrant gene activation of signaling pathways that subsequently predict the future of the disease. The various stages of cancer cells may be selectively hindered by several signaling transduction pathways. Recently, several studies have investigated the underlining mechanisms of $P$. urinaria and some possible targeted pathways in the treatment of cancers as shown below (Table 1). 
TABLE 1: Modulation of critical signaling pathways by extracts or bioactive constituents of Phyllanthus urinaria.

\begin{tabular}{|c|c|c|c|c|}
\hline $\begin{array}{l}\text { Extract/bioactive } \\
\text { constituent }\end{array}$ & Cancer type & Study type & Mechanism & Reference \\
\hline $\begin{array}{l}\text { Aqueous and } \\
\text { methanolic }\end{array}$ & $\begin{array}{c}\text { Human melanoma (MeWo) cancer } \\
\text { cell line }\end{array}$ & In vitro & $\begin{array}{c}\text { Suppression of NF- } \kappa \text { B, MAPKs, Myc/Max, and } \\
\text { hypoxia pathways }\end{array}$ & {$[11]$} \\
\hline $\begin{array}{l}\text { Aqueous and } \\
\text { methanolic }\end{array}$ & Human prostate adenocarcinoma & In vitro & $\begin{array}{l}\text { Induce apoptosis via downregulation of NF- } \kappa \mathrm{B}, \mathrm{Myc} / \\
\text { Max, hypoxia, MAPK/ERK, and MAPK/JNK }\end{array}$ & {$[17]$} \\
\hline Ethanolic & $\begin{array}{l}\text { Metastatic A549 and Lewis lung } \\
\text { carcinoma and xenograft }\end{array}$ & $\begin{array}{l}\text { In vitro and } \\
\text { in vivo }\end{array}$ & Inhibition of AP- 1 and NF- $\kappa$ B binding activity & {$[18]$} \\
\hline Corilagin & Glioblastoma cells U251 & In vitro & $\begin{array}{l}\text { Arrest cell cycle at G2/M phase and decreased NF- } \kappa \text { B } \\
\text { pathway }\end{array}$ & {$[19]$} \\
\hline Ethanolic & Human osteosarcoma cell Saos-2 & In vitro & $\mathrm{AKT}$ and ERK pathways inhibition & {$[20]$} \\
\hline $\begin{array}{l}\text { Aqueous and } \\
\text { methanolic }\end{array}$ & Human lung (A549) cancer cell line & In vitro & Raf-MEK-ERK and hypoxia pathways suppression & {$[10]$} \\
\hline $\begin{array}{l}\text { Aqueous and } \\
\text { methanolic }\end{array}$ & Breast carcinoma cells (MCF-7) & In vitro & Inhibition of ERK1/2 and hypoxia pathways & {$[21]$} \\
\hline Geraniin & Breast carcinoma cells (MCF-7) & In vitro & Modulation of p38 MAPK to induce apoptosis & {$[22]$} \\
\hline Gallic acid & $\begin{array}{c}\text { Human nasopharyngeal carcinoma } \\
\text { cells }\end{array}$ & In vitro & Inhibition of p38 MAPK & {$[23]$} \\
\hline
\end{tabular}

2.4. NF- $\kappa B$ Pathway. NF- $\kappa \mathrm{B}$ is a family of transcription factors that play a critical role in regulating different biological activities including inflammation, cell growth, and apoptosis [24, 25]. Moreover, a growing body of evidence suggests an important link between NF- $\kappa$ B and cancer cell proliferation, development, and inhibition of apoptosis [26-29].

NF- $\kappa$ B transcription complex in mammals comprises 5 homologous protein subunits (RelA/p65, c-Rel, RelB, p50/ $\mathrm{NF}-\kappa \mathrm{B} 1$, and $\mathrm{p} 52 / \mathrm{NF}-\kappa \mathrm{B} 2)$ kept in the cytoplasm after dimerization by $\mathrm{I} \kappa \mathrm{Bs}$. Above $\mathrm{I} \kappa \mathrm{B}$ bound $\mathrm{p} 50$, p 65 dimer is the IKK complex, comprising catalytic IKK $\alpha$ and IKK $\beta$ and regulator IKK $\gamma /$ NEMO protein subunits [30]. IKK complex activation in response to various stimuli phosphorylates the $\mathrm{I} \kappa \mathrm{B} s$, which subsequently targets them for ubiquitination and degradation by the $26 \mathrm{~S}$ proteosome [31]. The liberated $\mathrm{NF}-\kappa \mathrm{Bs}$ translocate to the nucleus and begin transcriptional activities of activated target genes for cellular effects such as cell growth, proliferation, apoptosis, and inflammation. NF$\kappa \mathrm{B}$ is activated by a variety of stimuli and plays a critical role as both tumor promoter and suppressor [32, 33]. However, chemotherapy-induced NF- $\kappa \mathrm{B}$ activation is context dependent and relates to different gene expressions [34]. Therefore, NF- $\kappa$ B inhibitors must be tried and applied with caution over prolonged period because of probable unpleasant adverse reactions. Nevertheless, natural medicines compared with their synthetic ones are thought about to have less adverse effects due to their history of prolonged usage.

Plumbagin, a plant-derived compound, dose dependently upregulated ROS and inhibited NF- $\kappa$ B by suppressing nuclear translocation of $\mathrm{p} 65$ and $\mathrm{I} \kappa \mathrm{Bs}$ degradation to induce apoptosis in the inhibition of lung cancer [35]. Quercetin inactivation of NF- $\kappa \mathrm{B}$ and activation of AP-1/JNK pathways induce apoptosis to inhibit human hepatoma cells [36]. Ellagic acid-induced apoptotic cell death on pancreatic cancer resulted from the suppression of NF- $\kappa$ B activity [37]. The pathology of various human diseases is associated with elevated NF- $\kappa \mathrm{B}$ signals; hence, there is the need for techniques to inhibit NF- $\kappa \mathrm{B}$ events for therapeutic interventions [38]. Gene modification or pharmacological control of NF- $\kappa \mathrm{B} 1$ events would provide a probable therapeutic approach for several cancers [39].

The aqueous and methanolic extracts of $P$. urinaria inhibit NF- $\kappa$ B via downregulation of p50 and p52 intracellular signals to suppress proliferation, angiogenesis, and migration in human melanoma cancer cells [11]. Tseng et al. showed that $P$. urinaria is a probable antimetastatic therapy due to its inhibition of DNA-binding action, NF- $\kappa$ B nuclear translocation, and AP-1 in a concentration-dependent fashion. Additionally, matrix metalloproteinase-2 (MMP-2), MMP-9, urokinase plasminogen activator, and their suppressors were downregulated [18]. Prostate cancer cells treated with $P$. urinaria suppressed p50 and p52 in the inhibition of NF- $\kappa$ B pathway via induction of apoptosis to inhibit tumor cell proliferation [17]. Corilagin downregulates the NF- $\kappa \mathrm{B}$ pathway to suppress cell proliferation at G2/M phase [19]. With regard to the above, it was expected that the suppression of NF- $\kappa \mathrm{B}$ activity by $P$. urinaria may serve to enhance the response of tumors to anticancer therapy.

2.5. PI3K/AKT Pathway. Phosphatase and tensin homolog (PTEN) is a tumor suppressor that negatively regulates the PI3K/AKT pathway via its capacity to transform phosphatidylinositol 3,4,5-trisphosphate (PIP3) to phosphatidylinositol 4,5-bisphosphate (PI4,5P2) [40]. The regulation of PTEN/PI3K/AKT pathway plays an important role in normal cellular activities associated with cell growth, proliferation, motility, survival, metabolism, and apoptosis.

Protein kinase $\mathrm{B} / \mathrm{AKTs}$ are a set of serine-threonine kinases, which serves as the principal node of the PI3K/AKT pathway and are usually upregulated in several human cancers. AKT has three homologous isoforms-AKT 1, AKT 2, and AKT 3-which are widespread. AKT hyperactivation in cancers is due to the alteration, functional loss, or amplification of AKT 1, AKT 2, and AKT 3 genes, PTEN/P13K, 
and catalytic alpha polypeptide (PIK3CA) gene [41]. Erroneous activation of $\mathrm{P} 13 \mathrm{~K} / \mathrm{AKT}$ signals play a critical function that contributes cell growth, proliferation, and suppression of apoptosis in various human cancers [42]. It has been demonstrated that PTEN upregulation inhibits cell cycle advancement and AKT phosphorylation to promote apoptosis of cancer cells [43]. PTEN deletion or functional loss hyperactivates AKT, a key downstream P13K target to induce cell growth and survival [44-47]. Hispidulin inactivates the P13K/AKT pathway in the induction of apoptosis to exert an inhibitory effect on HepG2 cells [48]. TRIM29 modulates $\mathrm{P} 13 \mathrm{~K} / \mathrm{AKT}$ to suppress thyroid carcinoma via induced apoptosis [49]. The induction of apoptosis through the mitochondrial pathway by oxymatrine inactivated the PI3K/AKT pathway in the suppression of human osteosarcoma cell growth [50]. Zhou et al. demonstrated in both in vivo and in vitro studies that geraniin, a bioactive compound of $P$. amarus, inhibits the proliferation of colorectal cancer through induction of apoptosis by downregulating $\mathrm{P} 13 \mathrm{~K} / \mathrm{AKT}$ activity [51].

$P$. Urinaria extract inhibited the urokinase-type plasminogen (u-PA) activator in the human osteosarcoma Saos-2 cell line via suppression of AKT and ERK pathways to prevent cell invasion and migration [20]. Also, the inhibition of the PI3K/AKT, MAPKs, and hypoxia pathways by $P$. urinaria suppressed the growth of prostate cancer cells via induced apoptosis [17]. The suppression of cancers is associated with the inhibition of P13K/AKT, which is consistent with the possibility that $P$. urinaria suppresses the $\mathrm{P} 13 \mathrm{~K} / \mathrm{AKT}$ pathway in the inhibition of tumor growth.

2.6. MAPKs Signaling Pathways. The mitogen-activated protein kinases (MAPKs or MAP) are a set of related protein kinases consisting of seven subgroups with three classical types including extracellular signal-regulated kinase (ERK), c-jun N-terminal kinase (JNK), and p38 MAPK, which function in cell growth, proliferation, and apoptosis. Responses of these three classical MAPKs differ in sensitivities from different cell types and different stimuli [52]. In response to different stimuli, active Ras activates Raf (MAPK $\mathrm{KKK}$ ), which in turn activates MAPK kinases (MKKs) for transcriptional activities to produce cellular effects. MAPKs have been implicated in the development of many cancers including breast cancer, hepatoma, colon cancer, lung cancer, and liver cancer [53-57]. Ginsenoside 20(S)-protopanaxadiol is a probable therapeutic agent due to its modulation of the EGFR-mediated MAPK pathway to suppress triple-negative breast cancer [58]. Investigation has revealed that corilagin, an active ingredient obtained from P. niruri, blocks TGF- $\beta$ to inactivate AKT/ERK activity to prevent ovarian cancer cell growth [59]. Teriflunomide downregulation of MMP-9, epithelial-mesenchymal transition (EMT), and inhibition of Src/FAK was achieved through the regulation of MAPK pathway to prevent the growth of cancer cell by inducing apoptosis [60]. Therefore, MAPK suppressors are being exploited as potential anticancer chemotherapeutic agents.
P. Urinaria exertion of antimetastatic effect on lung cancer leads to the downregulation of MMP-2, MMP-7, and MMP-9 via suppression of Raf-MEK-ERK and hypoxia signaling pathways [10]. A previous report indicates that $P$. urinaria inhibited angiogenesis, proliferation, and $\mathrm{mi}-$ gration of human melanoma cell via inactivation of MAPK/ ERK, MAPK/P38 and upregulation of MAPK/JNK pathways [11]. Additionally, c-myc, HIF-1 $\alpha$, and VEGF expression were significantly downregulated. P. urinaria prevented metastasis of breast cancer through inhibition of ERK1/2 by downregulating matrix metalloprotein 2 and 9 and hypoxia pathways [21]. Geraniin, an active component of $P$. urinaria, has been reported to modulate p38 MAPK in the induction of apoptotic cell death to prevent the growth of MCF-7 [22]. Data from the treatment of human nasopharyngeal carcinoma cells suggest that $P$. urinaria gallic acid markedly suppressed AP-1/ETS-1-mediated MMP-1 transcription and matrix invasion by inhibiting the p38 MAPK pathway [23].

2.7. Phyllanthus urinaria and Apoptosis. Several important studies have scientifically proven that $P$. urinaria induces apoptosis in the inhibition of tumors. Corilagin, a bioactive compound of P. urinaria, induced apoptosis via both intrinsic and extrinsic pathways by downregulating procaspase-8, procaspase-3, PARP, Bcl-2, and procaspase- 9 and upregulation of caspase-8, cleaved PARP, caspase-9, and Bax modulated by reactive oxygen species production in the inhibition of breast cancer cells [61]. Huang et al. demonstrated that $P$. urinaria-induced apoptosis was characterized by DNA fragmentation, membrane blebbing, and formation of apoptotic bodies in the suppression of the viability of human cancer cells [62]. In another study, Huang et al. observed that $P$. urinaria inhibits Lewis lung carcinoma proliferation by increasing caspase- 3 and downregulating Bcl-2 in the induction of tumor cell apoptosis [7]. Furthermore, $P$. urinaria administration inhibited the growth of human nasopharyngeal carcinoma cell line through induction of apoptosis and decreased telomerase events by suppressing human telomerase reverse transcriptase, human telomerase-associated protein 1, and c-myc mRNA signal [63]. A more recent study [64] showed that P. urinaria mediates apoptosis via activation of both intrinsic and extrinsic pathways in the suppression of human osteosarcoma 143B cells [64]. Corilagin induces apoptosis by increasing caspase-3 activity to result in decreased mitochondrial membrane potential in a dose-dependent manner to inhibit ovarian cancer cells [65]. Also, P. urinaria alcohol extract induced apoptosis in the suppression of stomach cancer [66]. Various fractions prepared from the plant activated caspase- 3 and caspase- 8 and suppressed $\mathrm{Bcl}-2$ to induce apoptosis in the inhibition of cancer cells via suppression of telomerase [67]. The data therefore suggest that the induction of apoptosis is one of the anticancer mechanisms of P. urinaria (Table 2).

2.8. Antiangiogenic Activity of Phyllanthus urinaria. Angiogenesis, the formation of additional vasculature to provide nourishment, plays a critical function in tumor 
TABLe 2: Apoptotic effects of extracts or bioactive constituents of Phyllanthus urinaria in cancers.

\begin{tabular}{|c|c|c|c|c|}
\hline $\begin{array}{l}\text { Extract/bioactive } \\
\text { constituent }\end{array}$ & Cancer type & Study type & Mechanism & Reference \\
\hline Corilagin & $\begin{array}{l}\text { Breast carcinoma cells (MCF-7), } \\
\text { MDA-MB-231 and Xenograft }\end{array}$ & $\begin{array}{l}\text { In vitro } \\
\text { and in } \\
\text { vivo }\end{array}$ & $\begin{array}{l}\text { Downregulation of procaspase- } 8 \text {, procaspase- } 3 \text {, } \\
\text { PARP, Bcl-2, and procaspase- } 9 \text { and upregulation of } \\
\text { caspase- } 8 \text {, cleaved PARP, caspase- } 9 \text {, and Bax }\end{array}$ & {$[61]$} \\
\hline Aqueous & Human cancer cells & In vitro & $\begin{array}{l}\text { DNA fragmentation, membrane blebbing, and } \\
\text { formation of apoptotic bodies }\end{array}$ & {$[62]$} \\
\hline Aqueous & Lewis lung carcinoma cell line & In vitro & $\begin{array}{c}\text { Induce apoptosis via downregulation of Bcl-2 and } \\
\text { upregulation of caspase-3 }\end{array}$ & [7] \\
\hline Aqueous & $\begin{array}{c}\text { Human nasopharyngeal carcinoma } \\
\text { cell line }\end{array}$ & In vitro & $\begin{array}{l}\text { DNA fragmentation upregulated caspase-3 and } \\
\text { decreased Bcl-2 }\end{array}$ & {$[63]$} \\
\hline Aqueous & Human osteosarcoma 143B cells & In vitro & $\begin{array}{l}\text { Activation of Fas receptor/ligand expression, } \\
\text { upregulation of Bid, tBid, and Bax, and decreased } \\
\qquad \mathrm{Bcl}-2\end{array}$ & {$[64]$} \\
\hline Corilagin & Ovarian cancer cellSKOV3 & In vitro & $\begin{array}{l}\text { Upregulated caspase- } 3 \text { activity and loss of } \\
\text { mitochondrial membrane potential }\end{array}$ & {$[65]$} \\
\hline Alcohol & Stomach cancer cell line & In vitro & Apoptosis of MKN28 cell & {$[66]$} \\
\hline $\begin{array}{l}\text { Ethylene glycol, ethyl } \\
\text { acetate, methanol, and } \\
\text { water }\end{array}$ & $\begin{array}{l}\text { HEp-2 (alveolar epithelial } \\
\text { carcinoma cell line), MCF-7, HeLa } \\
\text { (cervical cancer line) }\end{array}$ & In vitro & Activate caspase- 3 , caspase- 8 , and suppress Bcl- 2 & {$[67]$} \\
\hline
\end{tabular}

Table 3: Antiangiogenic effects of extracts or bioactive constituents of Phyllanthus urinaria.

\begin{tabular}{|c|c|c|c|c|}
\hline $\begin{array}{l}\text { Extract/bioactive } \\
\text { constituent }\end{array}$ & Cancer type & Study type & Mechanism & Reference \\
\hline Aqueous & $\begin{array}{l}\text { Mice bearing Lewis lung } \\
\text { carcinoma cells, HUVECs }\end{array}$ & $\begin{array}{l}\text { In vivo and } \\
\text { in vitro }\end{array}$ & Suppressed neovascularization in mice & {$[68]$} \\
\hline $\begin{array}{l}\text { Aqueous and } \\
\text { methanolic }\end{array}$ & MeWo and PC-3HUVECs & In vitro & $\begin{array}{l}\text { Suppressed of migration, invasion, and microcapillary } \\
\text { like-tube structure formation in HUVECs }\end{array}$ & [69] \\
\hline Aqueous & $\begin{array}{c}\text { Human osteosarcoma xenograft } \\
\text { mice }\end{array}$ & In vivo & Inhibition of cluster of differentiation 31 & {$[70]$} \\
\hline Ellagic acid & $\begin{array}{l}\text { Chorioallantoic membrane in } \\
\text { chicken embryo }\end{array}$ & In vivo & Inhibition of MMP-2 & {$[71]$} \\
\hline Methanolic & $\begin{array}{c}\text { Male Sprague-Dawley rats, } \\
\text { HUVECs }\end{array}$ & $\begin{array}{l}\text { In vivo and } \\
\text { in vitro }\end{array}$ & Suppression of vascular growth and tube formation & {$[72]$} \\
\hline Aqueous & Hepatocellular carcinoma & $\begin{array}{l}\text { In vivo and } \\
\text { in vitro }\end{array}$ & Inhibition of migration & {$[73]$} \\
\hline
\end{tabular}

development and proliferation. It is facilitated by extracellular matrix breakdown by MMP. Proangiogenic molecules such as vascular endothelial growth factor upregulate antiapoptotic proteins to aid in the survival of new endothelial cells to promote angiogenesis. The development of angiogenic inhibitors is therefore essential in the induction of tumor cell apoptosis and inhibition of metastasis. In vivo study of $P$. urinaria in mice bearing Lewis lung carcinoma resulted in significantly decreased tumor progression with marked inhibition in tumor size. Additionally, the extract inhibited tumor neovascularization and induced apoptosis with limited cytotoxicity [68]. A previous report indicates that among four Phyllanthus species administered on MeWo, PC-3, and human umbilical vein endothelial cells, $P$. urinaria demonstrated the strongest antimetastatic and antiangiogenic effect in a dose-dependent fashion via reduction in matrix metalloproteinase-2 [69]. The underlying mechanism of the $P$. urinaria suppression of human osteosarcoma xenograft growth in mice was due to the induction of apoptosis characterized by increased $\mathrm{Bax} / \mathrm{Bcl}-2$ ratio and inhibition of cluster of differentiation 31 via regulation of both mitochondrial fission and fusion proteins [70]. Ellagic acid, a bioactive component of $P$. urinaria, exhibits in vivo antiangiogenic effect by inhibiting MMP-2 [71]. The methanolic extract of $P$. urinaria at $100 \mu \mathrm{g} / \mathrm{mL}$ inhibited vessel outgrowth and tube formation at $56.7 \%$ and $35.6 \%$, respectively [72]. The aqueous extract of the plant inhibits migration and delays progression of $\mathrm{HBV}$-associated hepatocellular carcinoma [73]. Tumor progression can therefore be suppressed by the regulation of angiogenesis. These results indicate that $P$. urinaria can serve as an angiogenesis inhibitor to suppress cancers (Table 3 ).

2.9. Phyllanthus urinaria in Clinical Trials. Traditionally, several herbal medicines are purported to have anticancer properties, and some have been proven scientifically. $P$. urinaria is claimed to possess anticancer activity as exhibited by in vitro and very few in vivo studies. To date, the few clinical trials conducted so far were carried out in hepatitis B patients. The recent clinical trial (NCT01210989) was conducted in nonalcoholic steatohepatitis patients, 
where 60 patients were enrolled onto a placebo-controlled parallel-group double-blind randomized controlled trial. The results revealed decreased hepatic steatosis and ballooning grades within the P. urinaria group, which were of limited clinical significance. Moreover, no significant difference was associated with the alterations in fasting glucose, lipid profile, alanine aminotransferase, and aspartate aminotransferase [74]. Cirrhosis patients treated with $P$. urinaria over a period of three years revealed that, compared with their controls, the extract delayed or prevented the progression of hepatitis B virus-associated cirrhosis to hepatocellular carcinoma [75]. There is therefore the need for more rigorous and effective studies of $P$. urinaria as an anticancer agent to pave way for future clinical trials.

2.10. Safety Profile of Phyllanthus urinaria. Although numerous data abound to show the therapeutic relevance of $P$. urinaria in various forms of cancer, there is paucity of evidence in the scientific literature about its toxicity profile. Most drug candidates fail to go through the drug development process due to serious toxicity. As a result, it is crucial that toxicity assessment is conducted for all promising phytochemical compounds and/or medicinal plants like $P$. urinaria. Cell viability assay with corilagin, a compound derived from $P$. urinaria, showed that it did not induce cytotoxicity in various normal human cells up to a concentration of $100 \mu \mathrm{M}$. Furthermore, in vivo studies indicated that the compound $(300 \mathrm{mg} / \mathrm{kg} /$ day) was safe in C5BL/6 mice. [76]. The ethanolic extract of the plant was found to prevent doxorubicin-induced cardiotoxicity. [77]. In a more current study, corilagin was shown to inhibit acetaminophen-induced hepatotoxicity by downregulating the inflammatory response and by inhibiting ERK/JNK MAPK and NF- $\kappa$ B signaling pathways [78]; whereas extracts from the plant inhibited growth of breast and lung carcinoma cells, they were observed to have lower toxicity in normal cells [8]. This was a corroboration of an earlier study that reported insignificant cytotoxicity in normal human skin and prostate cells. [9]. It can be deduced from the limited available data on the toxicity of $P$. urinaria that the plant is relatively nontoxic in both in vitro and in vivo experiments. Furthermore, it has cytoprotective potential, which could prove beneficial upon exposure to various organ and cellular toxicants.

2.11. Future Perspective. To improve the efficacy of phytochemicals, nano-based formulation can be considered due to their potential for the treatment of several diseases and cancers. The use of natural medicine-based nanoformulations in cancer therapy has advanced and overcome the disadvantages of the conventional cancer treatment approaches such as low specificity, high toxicity, multidrug resistance, and poor bioavailability. The nonspecificity of chemotherapy has long harmed normal cell proliferation rendering cancer patients immunocompromised with long-term adverse effects. Nanomedicines have the advantages such as high proximity, high specificity, and less adverse effects, which promote their effectiveness in improving patients' response and prolonged survival. Moreover, encapsulation of bioactive components in nanocarriers can upregulate stability, extend a compound's blood circulation time, and allow for regulated and prolonged drug release in vivo. The accumulation of natural product nano-based medicines at tumor sites permits their natural components to target the cancer cells passively or actively. In vivo and in vitro studies have been used to demonstrate the anticancer effect of several nanoencapsulated natural drug products $[79,80]$. Nguyen et al. reported that green silver nanoparticles formed from leaf extracts of Phyllanthus urinaria, Pouzolzia zeylanica, and Scoparia dulcis inhibited the growth of fungi [81]. Moreover, green silver nanoparticles formed from Phyllanthus amarus have also been shown to inhibit multidrug-resistant Pseudomonas aeruginosa strains [82]. Also, silver nanoparticles from Phyllanthus niruri leaves have exhibited excellent antibacterial activity against several multidrug-resistant pathogens in humans [83]. Reports indicate that corilagin and its metabolites have low bioavailability $[84,85]$. Recently, nanotechnology-based drug delivery systems have been very promising and can change the therapeutic front of tumor cell management. Therefore, combination of nanotechnology and natural medicines such as Phyllanthus urinaria and corilagin as an anticancer agent may improve therapeutic response and better the clinical outcome of patients.

\section{Conclusion}

Signaling pathways in many human cancers are erroneously activated; therefore, targeting such anomalies could be of great significance to cancer treatment. NF- $\kappa \mathrm{B}, \mathrm{P} 13 \mathrm{~K} / \mathrm{AKT}$, and MAPKs pathways are mostly activated in cancers, and currently few inhibitors targeting these pathways are either available or undergoing clinical trials.

This review demonstrates that $P$. urinaria inhibits cancer cell proliferation via inhibition of NF- $\kappa \mathrm{B}, \mathrm{P} 13 \mathrm{~K} / \mathrm{AKT}$, and MAPKs (ERK, JNK, P38) pathways to induction of apoptosis and prevents angiogenesis. Moreover, we observed that corilagin induces apoptosis via both the intrinsic and extrinsic pathways and ellagic acid can serve as an antiangiogenic agent. Additionally, there are limited data on in vivo administration of $P$. urinaria and no clinical trials have been conducted so far with reference to cancers. The comprehensive knowledge of $P$. urinaria on these distinct molecular targets will serve as baseline data to enhance its potential and transformation for commercial use. All in all, it is expected that understanding these fundamental mechanisms may help stimulate additional research to exploit Phyllanthus urinaria and other natural products for the development of probable novel anticancer therapies in the future.

\section{Conflicts of Interest}

The authors declare no conflicts of interest. 


\section{References}

[1] S.-H. Fang, Y. K. Rao, and Y.-M. Tzeng, "Anti-oxidant and inflammatory mediator's growth inhibitory effects of compounds isolated from Phyllanthus urinaria," Journal of Ethnopharmacology, vol. 116, no. 2, pp. 333-340, 2008.

[2] M. Ilangkovan, I. Jantan, H. F. Mohamad, K. Husain, A. Razak, and A. Faiz, "Inhibitory effects of standardized extracts of Phyllanthus amarus and Phyllanthus urinaria and their marker compounds on phagocytic activity of human neutrophils," Evidence-Based Complementary and Alternative Medicine, vol. 2013, Article ID 603634, 9 pages, 2013.

[3] C.-H. Lai, S.-H. Fang, Y. K. Rao et al., "Inhibition of Helicobacter pylori-induced inflammation in human gastric epithelial AGS cells by Phyllanthus urinaria extracts," Journal of Ethnopharmacology, vol. 118, no. 3, pp. 522-526, 2008.

[4] S.-G. Yeo, J. H. Song, E.-H. Hong et al., "Antiviral effects of Phyllanthus urinaria containing corilagin against human enterovirus 71 and Coxsackievirus A16 in vitro," Archives of Pharmacal Research, vol. 38, no. 2, pp. 193-202, 2015.

[5] G. Du, M. Xiao, S. Yu, M. Wang, Y. Xie, and S. Sang, "Phyllanthus urinaria: a potential phytopharmacological source of natural medicine," International Journal of Clinical and Experimental Medicine, vol. 11, no. 7, pp. 6509-6520, 2018.

[6] S.-T. Huang, K.-W. Bi, H.-M. Kuo et al., "Phyllanthus urinaria induces mitochondrial dysfunction in human osteosarcoma $143 \mathrm{~B}$ cells associated with modulation of mitochondrial fission/fusion proteins," Mitochondrion, vol. 17, pp. 22-33, 2014.

[7] S.-T. Huang, R.-C. Yang, L.-J. Yang, P.-N. Lee, and J.-H. S. Pang, "Phyllanthus urinaria triggers the apoptosis and Bcl-2 down-regulation in Lewis lung carcinoma cells," Life Sciences, vol. 72, no. 15, pp. 1705-1716, 2003.

[8] S. H. Lee, I. B. Jaganath, S. M. Wang, and S. D. Sekaran, "Antimetastatic effects of Phyllanthus on human lung (A549) and breast (MCF-7) cancer cell lines," PLoS One, vol. 6, no. 6, Article ID e20994, 2011.

[9] Y.-Q. Tang, I. B. Jaganath, and S. D. Sekaran, "Phyllanthus spp. induces selective growth inhibition of PC-3 and MeWo human cancer cells through modulation of cell cycle and induction of apoptosis," PLoS One, vol. 5, no. 9, Article ID e12644, 2010.

[10] S. H. Lee, I. B. Jaganath, R. Manikam, and S. D. Sekaran, "Inhibition of Raf-MEK-ERK and hypoxia pathways by Phyllanthus prevents metastasis in human lung (A549) cancer cell line," BMC Complementary and Alternative Medicine, vol. 13, no. 1, pp. 1-20, 2013.

[11] Y.-Q. Tang, I. B. Jaganath, R. Manikam, and S. D. Sekaran, "Inhibition of MAPKs, Myc/Max, NF $\kappa$ B, and hypoxia pathways by Phyllanthus prevents proliferation, metastasis and angiogenesis in human melanoma (MeWo) cancer cell line," International Journal of Medical Sciences, vol. 11, no. 6, p. 564, 2014.

[12] J. Lopez and S. Tait, "Mitochondrial apoptosis: killing cancer using the enemy within," British Journal of Cancer, vol. 112, no. 6, pp. 957-962, 2015.

[13] J. L. Arbiser, M. Y. Bonner, and L. C. Gilbert, "Targeting the duality of cancer," NPJ Precision Oncology, vol. 1, no. 1, pp. 1-7, 2017.

[14] W. Xu, L. Jing, Q. Wang et al., "Bax-PGAM5L-Drp1 complex is required for intrinsic apoptosis execution," Oncotarget, vol. 6, no. 30, Article ID 30017, 2015.

[15] M. Hassan, H. Watari, A. AbuAlmaaty, Y. Ohba, and N. Sakuragi, "Apoptosis and molecular targeting therapy in cancer," BioMed Research International, vol. 2014, Article ID 150845, 23 pages, 2014.

[16] D. K. Biswas, Q. Shi, S. Baily et al., "NF-B activation in human breast cancer specimens and its role in cell proliferation and apoptosis," Proceedings of the National Academy of Sciences, vol. 101, no. 27, pp. 10137-10142, 2004.

[17] Y.-Q. Tang, I. Jaganath, R. Manikam, and S. D. Sekaran, "Phyllanthus suppresses prostate cancer cell, PC-3, proliferation and induces apoptosis through multiple signalling pathways (MAPKs, PI3K/Akt, NF B, and Hypoxia)," Evidence-Based Complementary and Alternative Medicine, vol. 2013, Article ID 609581, 13 pages, 2013.

[18] H.-H. Tseng, P.-N. Chen, W.-H. Kuo, J.-W. Wang, S.-C. Chu, and Y.-S. Hsieh, "Antimetastatic potentials of Phyllanthus urinaria L on A549 and Lewis lung carcinoma cells via repression of matrix-degrading proteases," Integrative Cancer Therapies, vol. 11, no. 3, pp. 267-278, 2012.

[19] W.-T. Yang, G.-H. Li, Z.-Y Li et al., "Effect of corilagin on the proliferation and NF- $\kappa$ B in U251 glioblastoma cells and U251 glioblastoma stem-like cells," Evidence-Based Complementary and Alternative Medicine, vol. 2016, Article ID 1418309, 10 pages, 2016.

[20] K.-H. Lu, H.-W. Yang, C.-W. Su, K.-H. Lue, S.-F. Yang, and Y.-S. Hsieh, "Phyllanthus urinaria suppresses human osteosarcoma cell invasion and migration by transcriptionally inhibiting u-PA via ERK and Akt signaling pathways," Food and Chemical Toxicology, vol. 52, pp. 193-199, 2013.

[21] S. H. Lee, I. B. Jaganath, N. Atiya, R. Manikam, and S. D. Sekaran, "Suppression of ERK1/2 and hypoxia pathways by four Phyllanthus species inhibits metastasis of human breast cancer cells," Journal of Food and Drug Analysis, vol. 24, no. 4, pp. 855-865, 2016.

[22] J.-W. Zhai, C. Gao, W.-D. Ma et al., "Geraniin induces apoptosis of human breast cancer cells MCF-7 via ROS-mediated stimulation of p38 MAPK," Toxicology Mechanisms and Methods, vol. 26, no. 5, pp. 311-318, 2016.

[23] J.-H. S. Pang, J.-H. Yen, H.-T. Wu, and S.-T. Huang, "Gallic acid inhibited matrix invasion and AP-1/ETS-1-mediated MMP-1 transcription in human nasopharyngeal carcinoma cells," International Journal of Molecular Sciences, vol. 18, no. 7, p. 1354, 2017.

[24] M. Barkett and T. D. Gilmore, "Control of apoptosis by Rel/ NF- $\kappa \mathrm{B}$ transcription factors," Oncogene, vol. 18, no. 49, pp. 6910-6924, 1999.

[25] X. Dolcet, D. Llobet, J. Pallares, and X. Matias-Guiu, "NF-kB in development and progression of human cancer," Virchows Archiv, vol. 446, no. 5, pp. 475-482, 2005.

[26] V. Fernandez-Majada, C. Aguilera, A. Villanueva et al., "Nuclear IKK activity leads to dysregulated notch-dependent gene expression in colorectal cancer," Proceedings of the National Academy of Sciences, vol. 104, no. 1, pp. 276-281, 2007.

[27] K. W. Rahman, S. Ali, A. Aboukameel et al., "Inactivation of $\mathrm{NF}-\kappa \mathrm{B}$ by $3,3^{\prime}$-diindolylmethane contributes to increased apoptosis induced by chemotherapeutic agent in breast cancer cells," Molecular Cancer Therapeutics, vol. 6, no. 10, pp. 2757-2765, 2007.

[28] G. W. Tew, E. L. Lorimer, T. J. Berg, H. Zhi, R. Li, and C. L. Williams, "SmgGDS regulates cell proliferation, migration, and NF- $\kappa \mathrm{B}$ transcriptional activity in non-small cell lung carcinoma," Journal of Biological Chemistry, vol. 283, no. 2, pp. 963-976, 2008.

[29] J. Yang, W.-H. Pan, G. A. Clawson, and A. Richmond, "Systemic targeting inhibitor of $\kappa \mathrm{B}$ kinase inhibits melanoma 
tumor growth," Canadian Research, vol. 67, no. 7, pp. 3127-3134, 2007.

[30] D. M. Rothwarf, E. Zandi, G. Natoli, and M. Karin, "IKK- $\gamma$ is an essential regulatory subunit of the $\mathrm{I} \kappa \mathrm{B}$ kinase complex," Nature, vol. 395, no. 6699, pp. 297-300, 1998.

[31] M. Karin and Y. Ben-Neriah, "Phosphorylation meets ubiquitination: the control of NF- $\kappa \mathrm{B}$ activity," Annual Review of Immunology, vol. 18, no. 1, pp. 621-663, 2000.

[32] T. Luedde, N. Beraza, V. Kotsikoris et al., "Deletion of NEMO/ IKK $\gamma$ in liver parenchymal cells causes steatohepatitis and hepatocellular carcinoma," Cancer Cell, vol. 11, no. 2, pp. 119-132, 2007.

[33] D. J. Wang, N. M. Ratnam, J. C. Byrd, and D. C. Guttridge, "NF- $\kappa \mathrm{B}$ functions in tumor initiation by suppressing the surveillance of both innate and adaptive immune cells," Cell Reports, vol. 9, no. 1, pp. 90-103, 2014.

[34] K. J. Campbell, J. M. O’Shea, and N. D. Perkins, “Differential regulation of NF- $\kappa \mathrm{B}$ activation and function by topoisomerase II inhibitors," BMC Cancer, vol. 6, no. 1, pp. 1-9, 2006.

[35] T.-P. Xu, H. Shen, L.-X. Liu, and Y.-Q. Shu, "Plumbagin from Plumbago Zeylanica L induces apoptosis in human non-small cell lung cancer cell lines through NF- $\kappa \mathrm{B}$ inactivation," Asian Pacific Journal of Cancer Prevention, vol. 14, no. 4, pp. 2325-2331, 2013.

[36] A. B. Granado-Serrano, M. A. Martín, L. Bravo, L. Goya, and S. Ramos, "Quercetin modulates NF- $\kappa$ B and AP- $1 / \mathrm{JNK}$ pathways to induce cell death in human hepatoma cells," Nutrition and Cancer, vol. 62, no. 3, pp. 390-401, 2010.

[37] M. Edderkaoui, I. Odinokova, I. Ohno et al., "Ellagic acid induces apoptosis through inhibition of nuclear factor $\mathrm{kB}$ in pancreatic cancer cells," World Journal of Gastroenterology, vol. 14, no. 23, p. 3672, 2008.

[38] T. D. Gilmore and M. R. Garbati, "Inhibition of NF- $\kappa$ B signaling as a strategy in disease therapy," NF-kB in Health and Disease, vol. 349, pp. 245-263, 2010.

[39] H.-M. Shen and V. Tergaonkar, "NF $\kappa$ B signaling in carcinogenesis and as a potential molecular target for cancer therapy," Apoptosis, vol. 14, no. 4, pp. 348-363, 2009.

[40] B. D. Manning and A. Toker, "AKT/PKB signaling: navigating the network,” Cell, vol. 169, no. 3, pp. 381-405, 2017.

[41] J. Q. Cheng, C. W. Lindsley, G. Z. Cheng, H. Yang, and S. V. Nicosia, "The Akt/PKB pathway: molecular target for cancer drug discovery," Oncogene, vol. 24, no. 50, pp. 7482-7492, 2005.

[42] N. Hay, "The Akt-mTOR tango and its relevance to cancer," Cancer Cell, vol. 8, no. 3, pp. 179-183, 2005.

[43] Z. Dobbin and C. Landen, "The importance of the PI3K/AKT/ MTOR pathway in the progression of ovarian cancer," International Journal of Molecular Sciences, vol. 14, no. 4, pp. 8213-8227, 2013.

[44] C. D. Befani, P. J. Vlachostergios, E. Hatzidaki et al., "Erratum to: bortezomib represses HIF- $1 \alpha$ protein expression and nuclear accumulation by inhibiting both PI3K/Akt/TOR and MAPK pathways in prostate cancer cells," Journal of Molecular Medicine, vol. 91, no. 6, pp. 771-773, 2013.

[45] J. A. Engelman, J. Luo, and L. C. Cantley, "The evolution of phosphatidylinositol 3-kinases as regulators of growth and metabolism," Nature Reviews Genetics, vol. 7, no. 8, pp. 606-619, 2006.

[46] B. Stiles, V. Gilman, N. Khanzenzon et al., "Essential role of AKT-1/protein kinase $\mathrm{B} \alpha$ in PTEN-controlled tumorigenesis," Molecular and Cellular Biology, vol. 22, no. 11, pp. 3842-3851, 2002.
[47] S.-M. Yang, C. Huang, X.-F. Li, M.-Z. Yu, Y. He, and J. Li, "miR-21 confers cisplatin resistance in gastric cancer cells by regulating PTEN,” Toxicology, vol. 306, pp. 162-168, 2013.

[48] H. Gao, H. Wang, and J. Peng, "Hispidulin induces apoptosis through mitochondrial dysfunction and inhibition of P13k/ Akt signalling pathway in HepG2 cancer cells," Cell Biochemistry and Biophysics, vol. 69, no. 1, pp. 27-34, 2014.

[49] J. Xu, Z. Li, Q. Su, J. Zhao, and J. Ma, “TRIM29 promotes progression of thyroid carcinoma via activating P13K/AKT signaling pathway," Oncology Reports, vol. 37, no. 3, pp. 1555-1564, 2017.

[50] Y. Zhang, S. Sun, J. Chen et al., "Oxymatrine induces mitochondria dependent apoptosis in human osteosarcoma MNNG/HOS cells through inhibition of PI3K/Akt pathway," Tumor Biology, vol. 35, no. 2, pp. 1619-1625, 2014.

[51] L.-A. Zhou, T.-B. Liu, and H.-N. Lü, "Geraniin inhibits proliferation and induces apoptosis through inhibition of phosphatidylinositol 3-kinase/Akt pathway in human colorectal cancer in vitro and in vivo," Anti-Cancer Drugs, vol. 31, no. 6, pp. 575-582, 2020.

[52] J. Yue and J. M. López, "Understanding MAPK signaling pathways in apoptosis," International Journal of Molecular Sciences, vol. 21, no. 7, p. 2346, 2020.

[53] N. Arya, A. Arora, K. S. Vasu, A. K. Sood, and D. S. Katti, "Combination of single walled carbon nanotubes/graphene oxide with paclitaxel: a reactive oxygen species mediated synergism for treatment of lung cancer," Nanoscale, vol. 5, no. 7, pp. 2818-2829, 2013.

[54] C. Bodur, O. Kutuk, G. Karsli-Uzunbas, T. T. Isimjan, P. Harrison, and H. Basaga, "Pramanicin analog induces apoptosis in human colon cancer cells: critical roles for Bcl-2, Bim, and p38 MAPK signaling," PLoS One, vol. 8, no. 2, Article ID e56369, 2013.

[55] J. B. Foo, L. S. Yazan, Y. S. Tor et al., "Dillenia suffruticosa dichloromethane root extract induced apoptosis towards MDA-MB-231 triple-negative breast cancer cells," Journal of Ethnopharmacology, vol. 187, pp. 195-204, 2016.

[56] E. Lamy, C. Herz, S. Lutz-Bonengel, A. Hertrampf, M.-R. Márton, and V. Mersch-Sundermann, "The MAPK pathway signals telomerase modulation in response to isothiocyanate-induced DNA damage of human liver cancer cells," PLoS One, vol. 8, no. 1, Article ID e53240, 2013.

[57] L.-T. Lin, C.-J. Tai, S.-P. Chang, J.-L. Chen, S.-J. Wu, and C.-C. Lin, "Cinnamaldehyde-induced apoptosis in human hepatoma PLC/PRF/5 cells involves the mitochondrial death pathway and is sensitive to inhibition by cyclosporin A and z-VAD-fmk," Anti-Cancer Agents in Medicinal Chemistry, vol. 13, no. 10, pp. 1565-1574, 2013.

[58] B. Peng, R. He, Q. Xu et al., "Ginsenoside 20 (S)-protopanaxadiol inhibits triple-negative breast cancer metastasis in vivo by targeting EGFR-mediated MAPK pathway," Pharmacological Research, vol. 142, pp. 1-13, 2019.

[59] L. Jia, H. Jin, J. Zhou et al., "A potential anti-tumor herbal medicine, Corilagin, inhibits ovarian cancer cell growth through blocking the TGF- $\beta$ signaling pathways," BMC Complementary and Alternative Medicine, vol. 13, no. 1, pp. 1-11, 2013.

[60] O. Huang, W. Zhang, Q. Zhi et al., "Teriflunomide, an immunomodulatory drug, exerts anticancer activity in triple negative breast cancer cells," Experimental Biology and Medicine, vol. 240, no. 4, pp. 426-437, 2015.

[61] Y. Tong, G. Zhang, Y. Li et al., "Corilagin inhibits breast cancer growth via reactive oxygen species-dependent 
apoptosis and autophagy," Journal of Cellular and Molecular Medicine, vol. 22, no. 8, pp. 3795-3807, 2018.

[62] S.-T. Huang, R.-C. Yang, and J.-H. S. Pang, "Aqueous extract of Phyllanthus urinaria induces apoptosis in human cancer cells," The American Journal of Chinese Medicine, vol. 32, no. 2, pp. 175-183, 2004.

[63] S.-T. Huang, C.-Y. Wang, R.-C. Yang, C.-J. Chu, H.-T. Wu, and J.-H. S. Pang, "Phyllanthus urinaria increases apoptosis and reduces telomerase activity in human nasopharyngeal carcinoma cells," Complementary Medicine Research, vol. 16, no. 1, pp. 34-40, 2009.

[64] H.-Y. Wu, T.-K. Lin, H.-M. Kuo et al., "Phyllanthus urinaria induces apoptosis in human osteosarcoma 143B cells via activation of Fas/FasL-and mitochondria-mediated pathways," Evidence-Based Complementary and Alternative Medicine, vol. 2012, Article ID 925824, 13 pages, 2012.

[65] R. Attar, Z. B. Cincin, E. S. Bireller, and B. Cakmakoglu, "Apoptotic and genomic effects of corilagin on SKOV3 ovarian cancer cell line," Onco Targets and Therapy, vol. 10, pp. 1941-1946, 2017.

[66] J.-M. Ji, W.-J. Hu, L.-X. Yu, X.-P. Qian, and B.-R. Liu, "Inhibiting effect of Phyllanthus urinaria alcohol extract on human stomach cancer cell MKN28," Journal of Nanjing University of Traditional Chinese Medicine, vol. 1, 2010.

[67] P. Giridharan, S. Somasundaram, K. Perumal et al., "Novel substituted methylenedioxy lignan suppresses proliferation of cancer cells by inhibiting telomerase and activation of c-myc and caspases leading to apoptosis," British Journal of Cancer, vol. 87, no. 1, pp. 98-105, 2002.

[68] S.-T. Huang, R.-C. Yang, P.-N. Lee et al., "Anti-tumor and anti-angiogenic effects of Phyllanthus urinaria in mice bearing Lewis lung carcinoma," International Immunopharmacology, vol. 6, no. 6, pp. 870-879, 2006.

[69] Y.-Q. Tang, I. B. Jaganath, R. Manikam, and S. D. Sekaran, "Phyllanthus spp. exerts anti-angiogenic and anti-metastatic effects through inhibition on matrix metalloproteinase enzymes," Nutrition and Cancer, vol. 67, no. 5, pp. 783-795, 2015.

[70] S.-T. Huang, C.-C. Huang, J.-M. Sheen et al., "Phyllanthus urinaria's inhibition of human osteosarcoma xenografts growth in mice is associated with modulation of mitochondrial fission/fusion machinery," The American Journal of Chinese Medicine, vol. 44, no. 7, pp. 1507-1523, 2016.

[71] S.-T. Huang, C.-Y. Wang, R.-C. Yang et al., "Ellagic acid, the active compound of Phyllanthus urinaria, exerts in vivo antiangiogenic effect and inhibits MMP-2 activity," EvidenceBased Complementary and Alternative Medicine, vol. 2011, Article ID 215035, 10 pages, 2011.

[72] K.-W. Ng, S. M. Salhimi, A. M. S. A. Majid, and K.-L. Chan, "Anti-angiogenic and cytotoxicity studies of some medicinal plants,” Planta Medica, vol. 76, no. 9, pp. 935-940, 2010.

[73] Y. Li, M. Jiang, M. Li et al., "Compound Phyllanthus urinaria $\mathrm{L}$ inhibits HBV-related HCC through $\mathrm{HBx}-\mathrm{SHH}$ pathway Axis inactivation," Evidence-Based Complementary and Alternative Medicine, vol. 2019, Article ID 1635837, 15 pages, 2019.

[74] V. W. S. Wong, G. L. H. Wong, A. W. H. Chan et al., "Treatment of non-alcoholic steatohepatitis with P hyllanthus urinaria: a randomized trial," Journal of Gastroenterology and Hepatology, vol. 28, no. 1, pp. 57-62, 2013.

[75] G.-D. Tong, X. Zhang, D.-Q. Zhou et al., "Efficacy of early treatment on 52 patients with preneoplastic hepatitis B virusassociated hepatocellular carcinoma by compound
Phyllanthus Urinaria L," Chinese Journal of Integrative Medicine, vol. 20, no. 4, pp. 263-271, 2014.

[76] L. J. Yang, R. H. Chen, S. Hamdoun et al., "Corilagin prevents SARS-CoV-2 infection by targeting RBD-ACE2 binding," Phytomedicine, vol. 87, p. 153591, 2021.

[77] L. Chularojmontri, S. K. Wattanapitayakul, A. Herunsalee, S. Charuchongkolwongse, S. Niumsakul, and S. Srichairat, "Antioxidative and cardioprotective effects of Phyllanthus urinaria L. on doxorubicin-induced cardiotoxicity," Biological and Pharmaceutical Bulletin, vol. 28, no. 7, pp. 1165-1171, 2005.

[78] F. C. Liu, H. P. Yu, A. H. Chou, H. C. Lee, and C. C. Liao, "Corilagin reduces acetaminophen-induced hepatotoxicity through MAPK and NF-kappaB signaling pathway in a mouse model," Am J Transl Res, vol. 12, no. 9, pp. 5597-5607, 2020.

[79] D. Cosco, D. Paolino, J. Maiuolo et al., "Ultradeformable liposomes as multidrug carrier of resveratrol and 5-fluorouracil for their topical delivery," International Journal of Pharmaceutics, vol. 489, no. 1-2, pp. 1-10, 2015.

[80] C. Li, X. Ge, and L. Wang, "Construction and comparison of different nanocarriers for co-delivery of cisplatin and curcumin: a synergistic combination nanotherapy for cervical cancer," Biomedicine \& Pharmacotherapy, vol. 86, pp. 628-636, 2017.

[81] D. H. Nguyen, J. S. Lee, K. D. Park et al., "Green silver nanoparticles formed by Phyllanthus urinaria, Pouzolzia zeylanica, and Scoparia dulcis leaf extracts and the antifungal activity," Nanomaterials, vol. 10, no. 3, p. 542, 2020.

[82] K. Singh, M. Panghal, S. Kadyan, U. Chaudhary, and J. P. Yadav, "Green silver nanoparticles of Phyllanthus amarus: as an antibacterial agent against multi drug resistant clinical isolates of Pseudomonas aeruginosa," Journal of Nanobiotechnology, vol. 12, no. 1, pp. 1-9, 2014.

[83] P. Kathireswari, S. Gomathi, and K. Saminathan, "Plant leaf mediated synthesis of silver nanoparticles using Phyllanthus niruri and its antimicrobial activity against multi drug resistant human pathogens," International Journal of Current Microbiology and Applied Sciences, vol. 3, pp. 960-968, 2014.

[84] Z. Yisimayili, X. Guo, H. Liu et al., "Metabolic profiling analysis of corilagin in vivo and in vitro using high-performance liquid chromatography quadrupole time-of-flight mass spectrometry," Journal of Pharmaceutical and Biomedical Analysis, vol. 165, pp. 251-260, 2019.

[85] B. Zheng, D. Chen, X. Yang et al., "Development and validation of an UPLC-PDA method for the determination of corilagin in rat plasma and its application to pharmacokinetic study," Journal of Chromatography B, vol. 1031, pp. 76-79, 2016. 